\title{
A Rare Case of Peritoneal Larval Cestodiosis by Mesocestoides from Aydın Region in Turkey
}

\author{
Osman Selçuk Aldemir $^{1 *}$, Güneş Erdoğan² \\ ${ }^{1 *}$ Adnan Menderes University, Faculty of Veterinary Medicine, Department of Parasitology, 09100 Aydin, Turkey \\ ${ }^{2}$ Adnan Menderes University, Faculty of Veterinary, Department of Obstetrics and Gynecology, 09100 Aydin, Turkey
}

\section{A R T I C LE IN F O}

Article history:

Received 05 May 2014

Accepted 20 May 2014

Available online, ISSN: 2148-127X

\section{Keywords:}

Parasitological examination

Peritoneal tetrathyridiosis

Ultrasonographic diagnosis of

Mesocestoides spp,

Cestode larval infection

Cat

\section{${ }^{*}$ Corresponding Author:}

E-mail: osaldemir@adu.edu.tr
A B S T R A C T

A case report was presented from the peritonea of a 3 year-old mixed breed stray cat weighing $3.2 \mathrm{~kg}$ was referred to the Adnan Menderes University, Faculty of Veterinary Medicine, Clinic of Obstetrics and Gynecology for spaying. On physical examination her body condition and warm were normal but mild diarrhoea was detected. After physical and ultrasonographic examination, white larvae-like structures were observed within the abdominal cavity. These structures were collected in saline solution for parasitological examination. On parasitological examination, one hundred eleven larvae were found in the peritonea. After examining macroscopically and microscopically these larvae were identified as L2 stage of Mesocestoides spp. This is the first report from Aydin in Turkey, based on morphological characteristics in this study.

\section{Introduction}

Mesocestoides are tapeworms in the order Cyclophyllidea; the adult stage of Mesocestoides sp. occurs mainly in foxes and only rarely in cats and dogs. Adult worms live in the small intestine of carnivores and rarely in birds and humans (Foronda et al., 2007; Gallas et al., 2011). Immature form (Tetrathyridia) of Mesocestoides sp., are found in the abdominal cavity of a great variety of intermediate hosts such as rodents, small reptiles and birds (Eberhard 1999; Padgett and Boyce 2005). The peritoneal larval cestodiasis has been diagnosed in dogs and cats in western Europe and western asia, but the majority of cases have been reported from western North America (Crosbie et al., 1998; Padgett et al., 2005).

Some cases of Feline peritonal larval cestodiosis by Mesocestoides had been reported (Crosbie et al., 1998; Gallas et al., 2011). This is the first report from Aydin in Turkey.

\section{Case History}

A 3 year-old mixed breed stray cat weighing $3.2 \mathrm{~kg}$, was referred to the Adnan Menderes University, Faculty of Veterinary Medicine, Clinic of Obstetrics and Gynecology, for spaying.

\section{Clinical Examination}

On physical examination, her body condition and warm were normal but mild diarrhoea was detected. During ultrasonographic examinations, there was no pathology at genital tract and ovaries, but some hyperechoic echoes in abdominal cavity (Fig. 1) were noticed. After physical and ultrasonographic examination, her situation was appropriated for ovariohysterectomy operation under genereal anaesthesia. While performing ventral midline experimental laparotomy, numerous small, white larvae-like structures were observed within the abdominal cavity. These structures were collected in saline solution for parasitological examination. Finding the as intensive larvae invasion, it was decided that ovariohysterectomy operation was not appropriated for this queen. After that, abdominal wall was closed with sutures without being ovariohysterectomized. However, a hour after surgery, the queen died from cardiac fibrillation.

\section{Diagnosis}

On parasitological examination, the larvae were characterized as unsegmented, with an unarmed scolex, four elongate oval suckers and no rostellum. These 
features indicated them to be the second larval stage of a Mesocestoides species (Fig. 2).

A total of 111 alive larvae were collected from the cat. The remainders were non-motile and seen in the deep ventral region of the peritonea (Fig. 3).

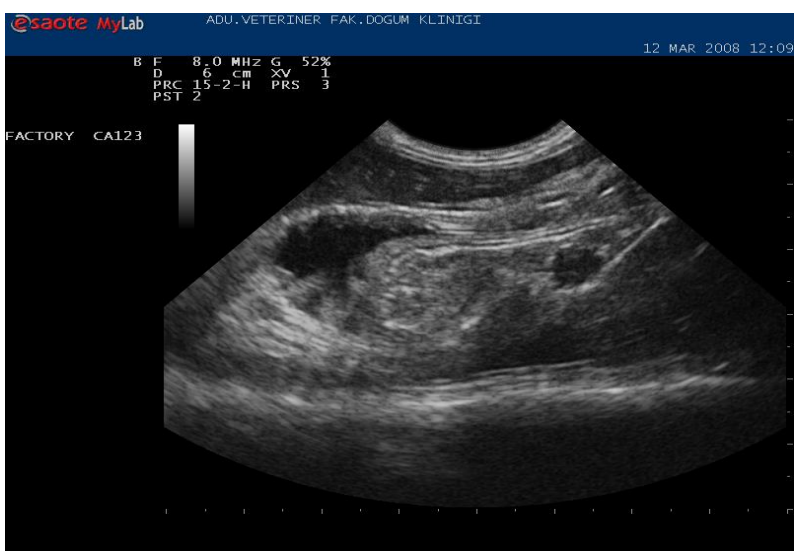

Figure 1 Ultrasonographic appearance of abdominal cavity.

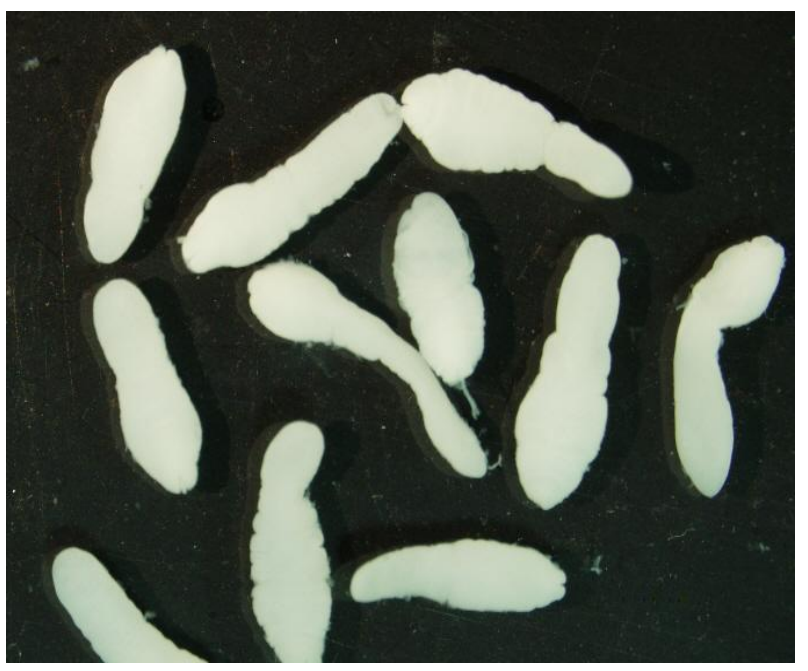

Figure 2 Mesocestoides spp. in the second-stage larvae. Magnification X 8

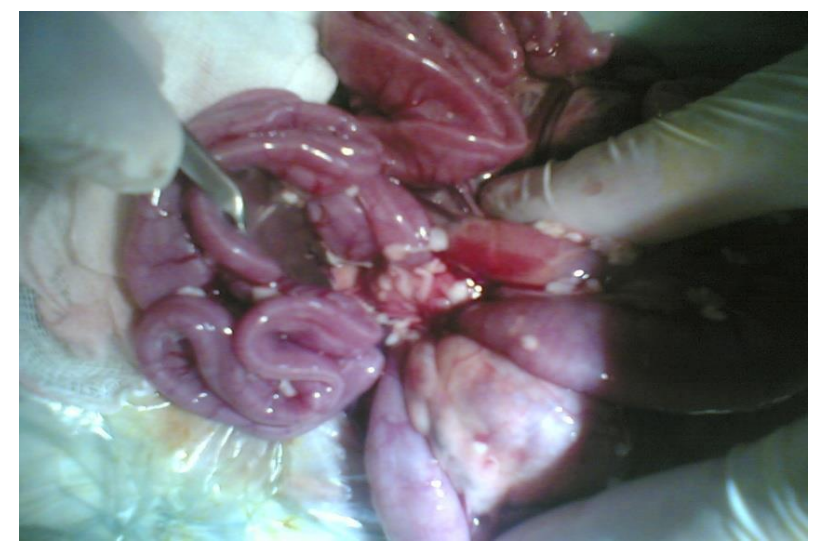

Figure 3 The presence of larvae in peritonea

\section{Discussion}

Tetrathyridium has been reported in various vertebrate hosts, including wild and domestic birds, snakes, frogs, rodents and dogs. Cat is also reported to harbour both the adult tapeworm and intermediate stage at the same time (Soulsby 1982).

Peritoneal tetrathyridiosis in cats has been recorded in classical textbooks (Soulsby 1982) and variously attributed to larval invasion by Mesocestoides sp. and Taenia sp. Larval cestode masses in cats and primates have been identified as spargana of Spirometra sp. However, in this case the proliferative characteristics of the parasite suggested Mesocestoides sp. or Taenia sp. The four basic forms of taeniid metacestodes were considered in differential diagnosis.

Tetrathyridium caused by genus Mesocestoides is likely to be underdiagnosed and has previously been recorded mainly in the USA (Williams et al., 1985) and rarely in Turkey in a peafowl (Toplu et al., 2006). Clinical signs of the tetrathyridia range from no symptoms to a severe clinical picture including abdominal enlargement, anorexia, vomiting, ascites and peritonitis (Eberhard 1999; Soulsby 1982). In the case described here, tetrathyridium were incidentally discovered during an exploratory laparotomy. The acute clinical condition of the cat in this report was most likely caused by cestode larval infection. The parasitic material found in this case consisted of fluid-filled cysts with no further morphological structures for specification. No larvae were found within the cysts which were thus considered sterile.

\section{References}

Crosbie PR, Boyce WM, Platzer EG, Nadler SA. 1998. Diagnostic procedures and treatment of eleven dogs with peritoneal infections caused by Mesocestoides spp. J Am. Vet. Med. Assoc., 213, 1578-1583.

Eberhard ML. 1999. Georgis' Parasitology for Veterinarians. In, Bowman DD, Lynn RC (Eds): Diagnostic Parasitology. 7th ed., pp. 361-367. WB Saunders Company, Philadelphia.

Foronda P, Pérez Rivero A, María A, Morales S, Kabdur A, Ana C, González M, Ricalde AQ, Feliu C, Valladares B. 2007. First larval record of Mesocestoides in carnivora of Tenerife (Canary Islands). J. Parasitol., 93(1):138-142

Gallas M, Silveira EF. 2011. Mesocestoides sp. (Eucestoda, Mesocestoididae) parasitizing four species of wild felines in Southern Brazil. Rev. Bras. Parasitol., Vet 20(2):168-170

Padgett KA, Boyce WM. 2005. Ants as first intermediate hosts of Mesocestoides on San Miguel Islan, USA. J. Helminthol., 79: $67-73$.

Soulsby, EJL. Helminths, 1986. Artropods and Protozoa of Domesticated Animals. 7.th ed., 809 p., Baillier Tindall, London.

Toplu N, Sarımehmetoglu O, Metin N, Eren H. 2006 Pleural and peritoneal tetrathyridiosis in a peafowl. Vet. Rec., 158: 102103.

Williams JF, Lindsay M, Engelkirk P. 1985. Peritoneal cestodiasis in a dog. J. Am. Vet. Med. Assoc., 186: 11031105 . 